\title{
Biodegradation of Tritium Labeled Polychlorinated Biphenyls (PCBs) by Local Salt Tolerant Mesophylic Bacillus Strains
}

\author{
Rasulov Bakhtiyor Abdughafurovich ${ }^{1}$, Kim Andrey Andreevich ${ }^{2}$, Lorenz Adrian ${ }^{3}$, \\ Yadgarov Khojiakbar Tashpulatovich ${ }^{1}$
}

${ }^{1}$ Institute of Genetics and Plant Experimental Biology, Uzbekistan Academy of Sciences, Tashkent, Uzbekistan; ${ }^{2}$ Institute of Nuclear Physics, Uzbekistan Academy of Sciences, Tashkent, Uzbekistan; ${ }^{3}$ Department Isotope Biogeochemistry, Helmholtz Centre for Environmental Research, Leipzig, Germany.

Email: bakhtiyor_1980@mail.ru

Received August $13^{\text {th }}, 2010$; revised September $8^{\text {th }}, 2010$; accepted September $13^{\text {th }}, 2010$.

\begin{abstract}
Salt-resistant Bacillus strains, isolated from agricultural soils in Uzbekistan, were tested for degradation activity towards a mixture of polychlorinated biphenyls (PCBs) under aerobic conditions. The study employed the use of tritium labeled PCB congeners and traced the tritium label in cultures with high salt content. The experiments show that most of the selected strains were able to adsorb a part of the radioactivity, indicating transformation of the added PCBs. Gas chromatography demonstrated transformation of $P C B$ s. The radioactive label was removed from several cultures by up to $91 \%$, indicating also mineralization of PCBs. The study suggests that the isolated strains might be good candidates for the bioremediation of contaminated high-salt soils in Uzbekistan and other Central-Asian countries.
\end{abstract}

Keywords: Bacillus, Biodegradation, PCBs, Salinity, Tritium Label

\section{Introduction}

Excessive use of fertilisers and pesticides in agriculture, primarily in the cotton and wheat plantations over the past decades, has resulted in significant contamination of soils not only in Uzbekistan, but also in a number of other Central Asian countries. Huge former cotton and wheat plantations now contain many different types of these chemicals.

One important example for these chemicals is the polychlorinated biphenyls (PCBs that have been widely used for numerous open and closed industrial applications. Commercial PCB mixtures were sold under the names Aroclor (Monsanto, USA), Phenoclor (Caffaro, Italy), Clophen (Bayer, Germany), Kanechlor (Kanegafuchi, Japan), and Sovol (former USSR). Due to their widespread use and their thermal and chemical stability they have also found their way to agricultural soil. PCBs are organic chemicals belonging to a class of hydrocarbons that are among the most hazardous environmental contaminants, as their physical and chemical properties especially their low water solubility and high lipophilicity lead to a high persistence in the environment and to bioaccumulation in the food chains [1,2].

Several bacteria have been described to degrade PCBs under aerobic conditions. Most of these bacteria also degrade biphenyls as a growth substrate. Such PCB degraders are mainly obligate aerobes, motile, gram negative rods. They can be enriched by cultivation with biphenyl or PCBs as a growth substrate on agar plates and are identified on agar plates by detecting clearing of biphenyl or PCB films around colonies. Biphenyl is mostly degraded by the initial action of a 2, 3-dioxygenase attack on the 2,3-carbons and meta-cleavage, producing benzoate. Similarly, there are many bacterial strains from the genera Pseudomonas [3], Arthrobacter [4], Vibrio, Aeromonas, Micrococcus, Acinetobacter, Bacillus, Rhodococcus [5], and Streptomyces that degrade mono-, di-, tri-, and several tetrachlorinated PCBs by meta-cleavage of non-chlorinated 2,3-carbons.

Soils in Uzbekistan vary considerably in their chemical composition and their salinity. The average soil salinity exceeds $40-60 \mathrm{mM} \mathrm{[6].} \mathrm{However,} \mathrm{in} \mathrm{some} \mathrm{provinces,}$ particularly in Karakalpakstan, and Khorezm, Syrdarya provinces the degree of salinity is several times higher than this. Overall climate and specific weather patterns 
play a major role in the impacts that soil salinity will have with regard to the different regional soils of Uzbekistan. Microbial biodegradation is the major process leading to transformation of organic chemicals in soil, and hence bioremediation is viewed as the most attractive approach to the ultimate destruction of exogenous agricultural chemicals added to cultivated soils. However, the efficiency of bioremediation of agrochemicals in soils depends on the soil conditions. Therefore, under the given climate and soil conditions in Uzbekistan, it appears necessary to use salt tolerant strains for bioaugmentation approaches. The application of microorganisms encoding contaminant-specific biodegradative pathways may provide the most cost-effective technology for the remediation of pollutant-contaminated sites. This type of technology may also be the most acceptable for the public because it represents a natural process that is essentially taking advantage of nature's recycling abilities. The most effective and acceptable bioremediation systems strive for complete mineralization of pollutants to inorganic products.

The aim of our research was to investigate the biodegradation of PCBs in the presence of sodium chloride the main source of salinity in the soil. Therefore, we used salt tolerant bacterial strains of the genus Bacillus from our strain collection and tested them for PCB degradation capability.

\section{Materials and Methods}

\subsection{Strains}

We used a bacterial strain collection that was set up in a number of state projects on biodegradation of hazardous organic pesticides, such as PCBs, HCCH (hexachlorecyclohexane), DDD (1,1-di(4'-chlorophenyl)-2,2 dichloroethane) and DDT (1,1-di(4'-chlorophenyl)-2,2,2 trichloroethane).

\subsection{Culture Medium}

The strains were cultured in synthetic mineral medium with the following additions $(\mathrm{g} / \mathrm{l}): \mathrm{NaCl}-0.5 ; \mathrm{KH}_{2} \mathrm{PO}_{4}-$ $0.7 ;\left(\mathrm{NH}_{4}\right)_{2} \mathrm{HPO}_{4}-1.5 ; \mathrm{MgSO}_{4} \cdot 7 \mathrm{H}_{2} \mathrm{O}-0.5 ; \mathrm{pH}$ 7.3. As the sole source of carbon and energy, PCBs were added in a concentration of $20 \mu \mathrm{g} / \mathrm{ml}$. Incubation was carried out on a shaker at $28^{\circ} \mathrm{C}$ for 60 days.

\subsection{Labeling of PCBs}

Before labeling, the labeling system and the capture was washed with nitrogen and a mixture of hexane:acetone (1:1). PCBs were labeled by thermal activation of tritium with the help of a labeling tool developed in the laboratory of biological radiochemistry [7]. A solution of nonlabeled PCBs was inserted to the surface of the reaction retort, cooled with liquid nitrogen and vacuumized to $5 \times$ $10^{-3} \mathrm{~mm}$ mercury. Labeling was carried out in five cycles, with five times filling the system with gaseous tritium up to a pressure of $8 \times 10^{-3} \mathrm{~mm}$ mercury. Tritium was activated with a heated tungsten spiral three times with a 20 minute time interval between heating the spiral. The mixture of PCBs was analysed before and after the labeling via HPLC. The labeled PCBs were purified on silica gel in hexane $\left(\mathrm{R}_{\mathrm{f}}=0.78\right)$.

\subsection{GC Analyses}

$\mathrm{GC}$ analysis was done using an electron capture detector. A Chromaton N-Super column $(2 \mathrm{~m} \times 4 \mathrm{~mm})$ (Chemapol, Czech Republic) was used, with a corn size of 0.125-0.16 $\mathrm{mm}$, column temperature $200^{\circ} \mathrm{C}$, injector temperature $230^{\circ} \mathrm{C}$, detector temperature $260^{\circ} \mathrm{C}$; carrier gas $30 \mathrm{ml} /$ min, 5\% DS-200 (Chemapol, Czech Republic).

\subsection{Analysis of Accumulation of PCBs by the Strains}

Strains cultured on synthetic agar-solidified medium were transferred to liquid medium. After one day of incubation $300 \mu \mathrm{l}$ of culture $\left(10^{8} \mathrm{cells} / \mathrm{ml}\right)$ were transferred to a test tube containing $1 \mathrm{ml}$ synthetic medium and $20 \mu \mathrm{l}$ of the prepared solution of tritium-labeled PCBs in hexane. The tritium-labeled PCB was the sole carbon and energy source. The strains were incubated from several days up to two months at $28^{\circ} \mathrm{C}$ on a shaker. After incubation bacterial cells were separated by centrifugation at $6500 \mathrm{rpm}$ for $30 \mathrm{~min}$. Cells and supernatant were dried and PCBs were extracted with hexane.

\subsection{Analysis of PCBs Degradation by the Selected Strains}

Bacterial cells, cultured on the agar-solidified mineral medium, were transferred to liquid medium. After one day, $300 \mu \mathrm{l}\left(10^{8}\right.$ cells $\left./ \mathrm{ml}\right)$ of this culture were transferred into test tubes with $5 \mathrm{ml}$ liquid medium containing peptone $(1 \%)$ and $100 \mu \mathrm{g}$ of PCBs. In the controls, cells were killed by autoclaving for $30 \mathrm{~min}$. The strains were incubated in a thermostat at $28^{\circ} \mathrm{C}$ for 60 days. Then, cells were harvested by centrifugation. Pellets and supernatants were dried at $60^{\circ} \mathrm{C}$ and PCBs were extracted with a mixture of hexane and acetone $(1: 1, \mathrm{vol} / \mathrm{vol})$. The extracts were then analyzed by GC as described above.

\subsection{Analysis of Biodegradation of PCBs in the Soil}

Autoclaved soil samples (15 g each) were mixed with $100 \mu \mathrm{g}$ of PCBs in $5 \mathrm{ml}$ of hexane. Then, soil samples were dried to remove hexane from the samples. Each soil sample was inoculated with $300 \mu \mathrm{l}$ from one of the liq- 
uid-medium cultures $\left(10^{8}\right.$ cells $\left./ \mathrm{ml}\right)$. The control consisted of a PCBs containing soil sample without bacteria. During the two month incubation period all samples were kept humid by the addition of sterile water. After incubation, samples were dried at $60^{\circ} \mathrm{C}$ and PCBs were extracted with a mixture of hexane and acetone (1:1, $\mathrm{vol} / \mathrm{vol})$. The extracts were analyzed by GC as described above.

\section{Results}

We investigated the capability of selected pure Bacillus strains (denominated №№ 20, 22, 23, 24, 27, 28, 29, 30, 31 , and 32) to utilize tritium-labeled PCBs in liquid culture and soil. The strains were isolated from soils in Uzbekistan that were heavily polluted since more than 40 years. We added $0.1 \mathrm{mg}$ tritium-labeled PCBs solved in 5 $\mathrm{ml}$ of hexane to the bottom of the tubes. PCBs were then dried by complete evaporation of hexane. The applied radioactivity inserted with $0.1 \mathrm{mg}$ of tritium labeled PCBs amounted to $13,647 \mathrm{imp} / 10$ seconds. Finally, the tubes were inoculated with $5 \mathrm{ml}$ of bacterial cultures. The control sample consisted of sterilized medium. The tubes, containing the culture liquids of the strains, were incubated in the thermostat at $28^{\circ} \mathrm{C}$ for 10 days. After incubation the cultures were transferred to centrifuge tubes, and bacterial cell were pelleted at $8000 \mathrm{rpm}$ for $30 \mathrm{~min}$. The supernatant was then transferred to fresh culture tubes. The pellets, containing bacterial cells were dried and weighed. Supernatants (culture liquid) were also dried at $80^{\circ} \mathrm{C}$ until they were completely dry. From the dried samples of bacterial strains and culture liquid PCBs were extracted using a mixture of hexane and aceton (1:1, $\mathrm{vol} / \mathrm{vol}$ ) three times. The combined PCB extracts were again dried, dissolved in $100 \mu \mathrm{l}$ of hexane and analyzed for radioactivity. Radioactivity was measured by liquid-scintillation counting in PЖC-05 (Liquid Scintillation Radiometer) in a toluene scintillate cocktail (1 1 toluene containing $4 \mathrm{~g}$ of PPO and $0.05 \mathrm{~g}$ of POPOP). For standardization a volume of $25 \mu \mathrm{l}$ of a control solution was taken. Obtained data were then recalculated to account for the whole volume. The results are given in the Figure 1.

It was observed that a large part of the tritium label was incorporated into cell mass, showing that the PCBs were transformed and used for cell growth. Only a minor part was still found in the medium as non-evaporable substances. Another part of the tritium label was lost from the tubes either by the production of volatile tritium-labeled intermediates or by the transfer of tritium from the PCBs into water and successive evaporation during the analysis procedure. In the strains $B$. mycoides

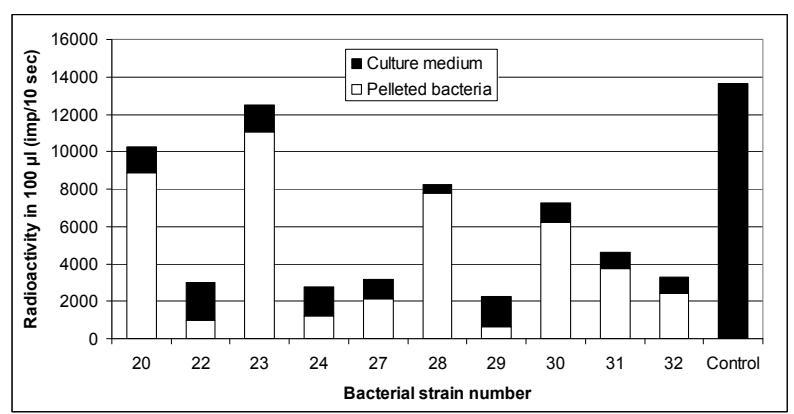

Figure 1. Radioactivity originating from tritium-labeled PCBs detected associated to the bacteria and the culture medium after incubation for 60 days.

20, B. subtilis 28 and Bacillus sp. 30 the percentage of the remaining radioactivity was between 53 and $75 \%$ (in the strain of Bacillus sp. 23 up to 91\%). In these strains (B. mycoides 20, Bacillus sp. 23, B. subtilis 28 and Bacillus sp. 30) between 86 and $95 \%$ of the remaining tritium was incorporated into the bacteria. In other strains the remaining radioactivity was $16-30 \%$, while the rest was lost. In the control sample no decrease of the radioactivity was observed. Therefore, we can exclude the possibility that there was an isotope exchange of tritium fixed in the added PCBs with hydrogen from the water phase.

The tritium-labeled PCBs remaining in the medium were analyzed by GC (Figure 2). It was observed that the spectra of PCB fractions changed during the incubation when bacteria were present. This proves active transformation of PCBs by the strains in the presence of $\mathrm{NaCl}$. The chromatogram of Sovol was also compared with the standard chromatograms of Aroclor (Aroclor 1016/1260 Standard, Aroclor 1221 Standard, Aroclor 1232 Standard, Aroclor 1242 Standard, Aroclor 1248 Standard, Aroclor 1254 Standard), available at the standard library NIST02. The chlorination spectrum of Sovol considerably differs from that of the various Aroclors, which were used for calibration of the mass-selective detector Hewlett-Packard HP5972. That is why we developed quantitative estimation of PCBs content in the tested samples. The obtained chromatograms from our incubations were reprocessed with MSD ChemStation Agilent Technologies in the overlay chromatogram regime. Chromatographic analysis of soil samples showed that they were rich in low chlorinated biphenyls.

The amount of tritium-labeled PCBs that was transformed and incorporated into the bacteria was recalculated from the incorporated radioactivity and the dry weight of bacterial cells. The results of these calculations are given in the Table 1 . Here, the high capacity of strains 20 and 23 to specifically transform PCBs be 

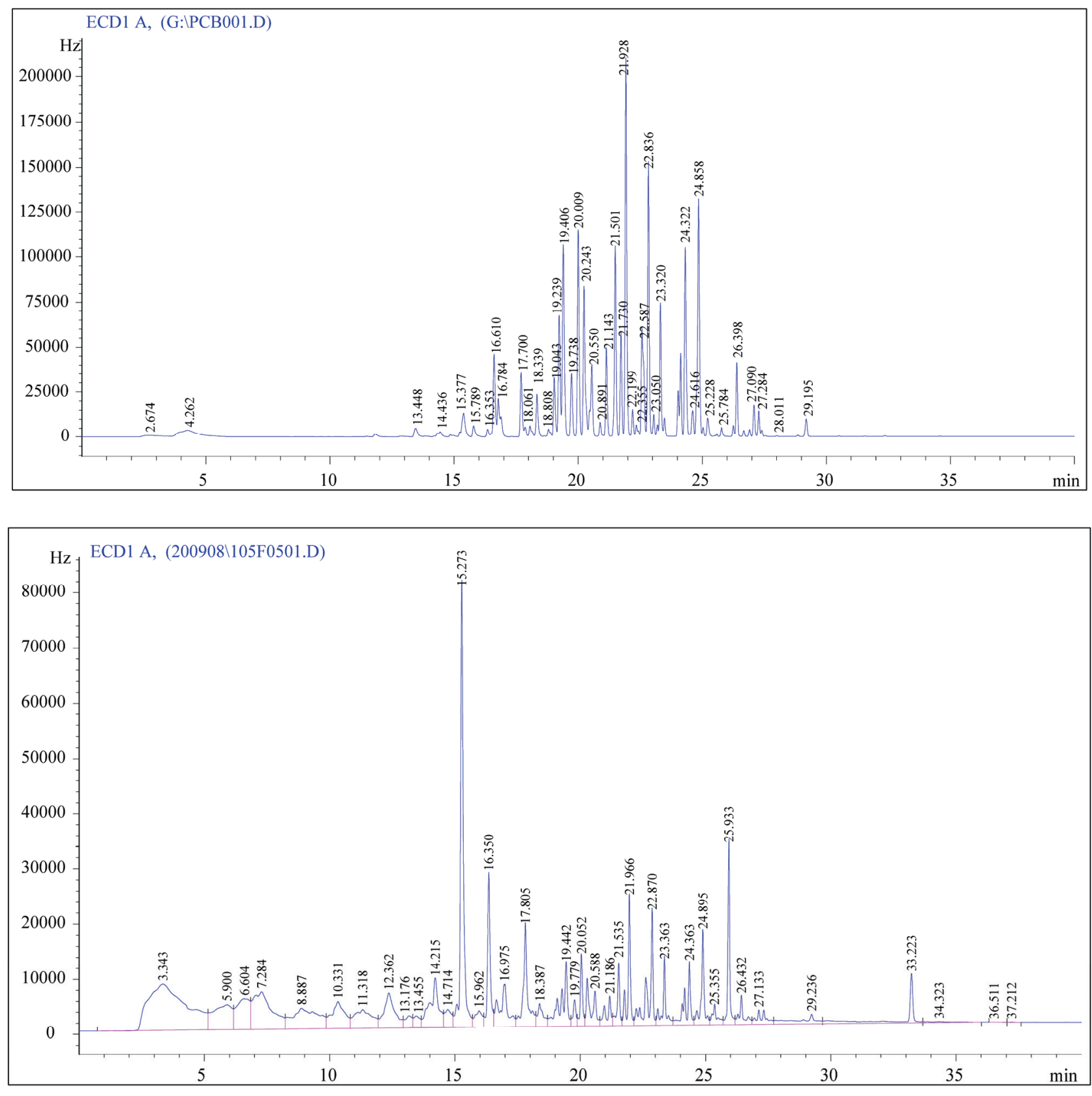

Figure 2. Chromatogram of extracted PCBs from Sovol-amended soils. Upper panel: control microcosm without bacteria; lower panel: PCB content after incubation with Bacillus sp. 23.

comes evident by values of above $50 \mu \mathrm{g}$ incorporated PCBs per mg of dry mass.

According to the literature monochlorinated biphenyls are more volatile than $\mathrm{PCB}$ isomers with 8-9 chlorine atoms. Also, the evaporation of the isomers depends on temperature $[8,9]$. It is necessary to point out that, under the hot climate conditions of Central Asia the temperature is one of the basic factors in the removal of PCBs from soil. In this climate the volatility of low chlorinate biphenyls are high. Therefore, even without the complete biodegradation of the lower chlorinated biphenyls, the toxicity of technical mixture of PCBs is greatly decreased, since low chlorinated (less than three chlorine atoms) are less toxic.

\section{Discussion}

Biodegradation of polychlorinated biphenyls has been shown and the activity of the products of $p c b$ genes in 
Table 1. Determination of tritium-labeled PCBs bound to the bacteria.

\begin{tabular}{ccccc}
\hline Strain & $\begin{array}{c}\text { Radioactivity bound to the } \\
\text { bacteria, imp/10 sec }\end{array}$ & $\begin{array}{c}\text { Dry weight of bacterial } \\
\text { cells }\end{array}$ & $\begin{array}{c}\text { Bound PCBs } \\
\text { (\% out of exposed radioactivity) }\end{array}$ & $\begin{array}{c}\text { Bound PCBs per mg dry } \\
\text { weight of bacterial cells }\end{array}$ \\
\hline B. mycoides 20 & 8,853 & $1.2 \mathrm{mg}$ & $64.87 \mu \mathrm{g}(64.87 \%)$ & $54.06 \mu \mathrm{g}$ \\
Bacillus sp. 22 & 984 & $2.3 \mathrm{mg}$ & $7.21 \mu \mathrm{g}(7.21 \%)$ & $3.13 \mu \mathrm{g}$ \\
sBacillus sp. 23 & 11,064 & $1.2 \mathrm{mg}$ & $81.07 \mu \mathrm{g}(81.07 \%)$ & $67.56 \mu \mathrm{g}$ \\
B. megaterium 24 & 1,208 & $1.1 \mathrm{mg}$ & $8.85 \mu \mathrm{g}(8.85 \%)$ & $8.05 \mu \mathrm{g}$ \\
B. subtilis 27 & 2,148 & $4.6 \mathrm{mg}$ & $15.74 \mu \mathrm{g}(15.74 \%)$ & $3.42 \mu \mathrm{g}$ \\
B. subtilis 28 & 7,768 & $10.3 \mathrm{mg}$ & $56.92 \mu \mathrm{g}(56.92 \%)$ & $5.54 \mu \mathrm{g}$ \\
B. megaterium 29 & 640 & $1.5 \mathrm{mg}$ & $4.69 \mu \mathrm{g}(4.69 \%)$ & $3.13 \mu \mathrm{g}$ \\
Bacillus sp. 30 & 6,216 & $3.8 \mathrm{mg}$ & $45.55 \mu \mathrm{g}(45.55 \%)$ & $11.99 \mu \mathrm{g}$ \\
B. megaterium 31 & 3,728 & $2.7 \mathrm{mg}$ & $27.32 \mu \mathrm{g}(27.32 \%)$ & $10.12 \mu \mathrm{g}$ \\
B. subtilis 32 & 2,396 & $20.9 \mathrm{mg}$ & $17.56 \mu \mathrm{g}(17.56 \%)$ & $0.84 \mu \mathrm{g}$ \\
\hline
\end{tabular}

different extreme environments has been documented. However, a strong effect of temperature on PCBs degradation has been found [10,11], and biphenyl dioxygenase was induced in psychorotolerant, polychlorinated biphenyl (PCBs) degrading Pseudomonas spp. [10,11]. However, biodegradation of polychlorinated biphenyls in salt affected environments still needs to be better clarified. There is no detailed data on salinity influence on biodegradation activity of catabolic strains, expression of $p c b$ genes, or synthesis and functioning of biphenyl dioxygenase(s). Therefore, in the present study we examined the biodegradative activity of catabolic strains, isolated from salt-rich, pesticide-polluted soils in Uzbekistan. Former pollutants included DDT, and $\mathrm{HCCH}$. The final concentration of $\mathrm{NaCl}$ in our study was $4 \%$, in which the tested strains survived in previous experiments. We observed degradation of the PCBs by several catabolic strains within 4 months of incubation, whereas other researchers incubated for 1 year in the temperature range from 4 to $66^{\circ} \mathrm{C}$ for microbial dechlorination of $2,3,4,6$ tetrachlorobiphenyl [8].

In all tested samples with salt-tolerant catabolic strains, PCB removal (up to $85-90 \%$ ) was much higher than with salt-intolerant catabolic strains of the same genus. That again proved normal catabolic functioning of the tested strains. It is important to note, that despite all strains belonged to the same genus, the products of biodegradation slightly varied in respect to the number of chlorine atoms and their positions in the ring. Especially, it was specific to the intermediates with penta- and hexachlorinated rings in the early stages of incubation. The chromatographic analysis of a technical mixture of PCBs showed abundant presence of highly chlorinated biphenyls, such as heptachlorobiphenyls $\left(2,2^{\prime}, 3,4,4^{\prime}, 5^{\prime}, 6-\right.$, 2,2',
3,3',4,- 6,6'-, and 2,2',3,4',5,5',6-heptachlorbiphenyl), hexachlorobiphenyls $\left(2,2^{\prime}, 3,4,4^{\prime}, 5^{\prime}-, 2,2{ }^{\prime} 4,4^{\prime}, 5,5^{\prime}-\right.$, and 2,2',3,-4,4',5'- hexachlorobiphenyls), and 2,2',4,5,5'pentachlorobi-phenyl. Also tri- and tetrachlorobiphenyls were detected in the mixture. After two and four months of incubation the amount of highly chlorinated biphenyls was strongly reduced in all inoculated samples. The chromatographic analysis of two month samples revealed that the amount of heptachlorobiphenyls and hexachlorebiphenyls was sharply reduced.

It is known that some bacterial strains can loose their biodegradation ability after introducing them into soil. Therefore, we performed additional tests on the functioning of the tested strains in soil. The strains were grown under model conditions in the soil with tritium labeled PCBs as the sole electron and carbon source. We found that most strains effectively mineralized PCBs resulting in decreasing level of tritium label in the soil with time (Figure 1).

Based on the obtained data we can conclude that the tested strains effectively utilize tritium-labeled PCBs and different $\mathrm{PCBs}$ metabolism intermediates in the presence of high concentrations of sodium chloride, which is the main contributor to salinity. In the $\mathrm{NaCl}$ containing microcosms the strains Bacillus sp. 23, B. mycoides 20, B. subtilis 28 and Bacillus sp. 30 transformed PCBs mainly to cell mass. Other strains most probably produced volatile compounds with low numbers of chlorine atoms, which evaporated during incubation and the analysis procedure. Herewith, we can suppose that practically all tritium labeled PCBs and their intermediates are incorporated into the strains, and the degree of biodegradation under model conditions in the soil was lower than that of cultures without soil. 
Based on our results we can recommend the use of all our investigated Bacillus strains to different extends as new biopreparations for the biodegradation of PCBs in the salt-affected soils in the Republic of Uzbekistan, and other Central Asian countries, including Kazakhstan, Turkmenistan, Tajikistan, and Kyrgyzstan, where technical PCBs were heavily used in industrial and agricultural processes.

\section{REFERENCES}

[1] J. F. Quensen, J. M. Tiedje and S. A. Boyd, "Reductive Dechlorination of Polychlorinated Biphenyls by Anaerobic Microorganisms from Sediment," Science, Vol. 242, No. 4879, 1988, pp. 752-754.

[2] V. A. McFarland and J. U. Clarke, "Environmental Occurrence, Abundance, and Potential Toxicity of Polychlorinated Biphenyl Congeners: Considerations for a Congener-Specific Analysis," Environment Health Perspect, Vol. 81, 1989, pp. 225-239.

[3] B. D. Erickson and F. J. Mondello, "Enhanced Biodegradation of Polychlorinated Biphenyls after Site-Directed Mutagenesis of a Biphenyl Dioxygenase Gene," Applied and Environmental Microbiology, Vol. 59, No. 11, 1993, pp. 3858-3862.

[4] E. S. Gilbert and D. E. Crowley, "Plant Compounds that Induce Polychlorinated Biphenyl Biodegradation by $\mathrm{Ar}$ throbacter sp. Strain B1B," Applied and Environmental Microbiology, Vol. 63, No. 5, 1997, pp. 1933-1938.

[5] A. W. Boyle, C. J. Silvin, J. P. Hassett, J. P. Nakas and S.W. Tanenbaum, "Bacterial PCB Biodegradation," Biodegradation, Vol. 3, No. 2-3, 1992, pp. 285-298.
[6] A. Abdullayev, "Azospirillum in Saline Soils of Uzbekistan," Ph.D Dissertation, Institute of Microbiology of Uzbekistan Academy of Sciences, Tashkent, 2006.

[7] A. A Kim, G. T. Djuraeva, P. V. Zinovev, I. I. Sadikov, A. A. Rylov, "A New Technique for Tritium Labeling of Complex Technical Mixture of PCB Congeners," Journal of Radioanalytical and Nuclear Chemistry, Vol. 272, No. 3, 2007, pp. 483-489.

[8] E. R. Master and W. W. Mohn, "Induction of bpha, Encoding Biphenyl Dioxygenase, in Two Polychlorinated Biphenyl-Degrading Bacteria, Psychrotolerant Pseudomonas Strain Cam-1 and Mesophilic Burkholderia Strain lb400," Applied and Environmental Microbiology, Vol. 67, No. 6, 2001, pp. 2669-2676.

[9] E. R. Master, N. Y. R. A. Leticia Gómez-Gil, J. B. Powlowski, W. W. Mohn and L. D. Eltis, "Biphenyl Dioxygenase from an Arctic Isolate is not Cold Adapted," Applied and Environmental Microbiology, Vol. 74, No. 12, 2008, pp. 3908-3911.

[10] Q. Wu, D. L. Bedard and J. Wiegel, "Effect of Incubation Temperature on the Route of Microbial Reductive Dechlorination of 2,3,4,6-Tetrachlorobiphenyl in Polychlorinated Biphenyl (PCB)-Contaminated and PCB-Free Freshwater Sediments," Applied and Environmental Microbiology, Vol. 63, No. 7, 1997, pp. 2836-2843.

[11] E. R. Master and W. W. Mohn, "Psychrotolerant Bacteria Isolated from Arctic Soil that Degrade Polychlorinated Biphenyls at Low Temperatures," Applied and Environmental Microbiology, Vol. 64, No. 12, 1998, pp. 4823-4829 . 